\title{
Ethical aspects of aging research
}

\author{
Enn Seppet • Mati Pääsuke • Maria Conte • \\ Miriam Capri $\cdot$ Claudio Franceschi
}

Received: 13 December 2010/Accepted: 10 May 2011/Published online: 22 May 2011

(C) Springer Science+Business Media B.V. 2011

\begin{abstract}
During the last 50-60 years, due to development of medical care and hygienically safe living conditions, the average life span of European citizens has substantially increased, with a rapid growth of the population older than 65 years. This trend places evergrowing medical and economical burden on society, as many of the older subjects suffer from age-related diseases and frailty. Coping with these problems requires not only appropriate medical treatment and
\end{abstract}

\section{E. Seppet $(\bowtie)$}

Department of Pathophysiology, Institute of General and Molecular Pathology, Faculty of Medicine, University of Tartu, 19 Ravila Street, 50411 Tartu, Estonia e-mail: enn.seppet@ut.ee

M. Pääsuke

Department of Kinesiology and Biomechanics, Faculty of Exercise and Sport Sciences, University of Tartu, Tartu, Estonia

e-mail: mati.paasuke@ut.ee

M. Conte · M. Capri - C. Franceschi CIG-Interdepartmental Centre Galvani, University of Bologna, Bologna, Italy e-mail: m.conte@unibo.it

M. Capri

e-mail: miriam.capri@ut.ee

C. Franceschi

e-mail: claudio.franceschi@unibio.it

M. Capri · C. Franceschi

Department of Experimental Pathology,

University of Bologna, Bologna, Italy social support but also extensive research in many fields of aging - from biology to sociology, with involvement of older people as the research subjects. This work anticipates development and application of ethical standards suited to dynamic advances in aging research. The aim of this review is to update the knowledge in ethical requirements toward recruitment of older research subjects, obtaining of informed consent, collection of biological samples, and use of stem cells in preclinical and clinical settings. It is concluded that application of adequate ethical platform markedly facilitates recruitment of older persons for participation in research. Currently, the basic ethical concepts are subjected to extensive discussion, with participation of all interested parties, in order to guarantee successful research on problems of human aging, protect older people from undesired interference, and afford their benefits through supporting innovations in research, therapy, and care.

Keywords Ethical issues - Human aging · Recruitment of subjects - Informed consent . Tissue samples $\cdot$ Stem cells $\cdot$ Older population

\section{Introduction}

Aging of European population during the last 50-60 years has been associated with an increasing fraction of population suffering from age-related diseases and muscle frailty, this change resulting in 
steadily growing healthcare costs. To oppose this trend, the European Commission has markedly expanded the funding for aging research, with the major goal to improve the quality of life among older people through revealing the mechanisms of the agerelated biological processes and diseases and discovering the means to decelerate aging. However, recruitment of older people in research is complicated due to compromised health, reduced mobility, and susceptibility to dangers owing to their age-related conditions. Therefore, while working with the older people, the researchers are expected to strictly obey the basic ethical principles, such as beneficence (doing good), non-maleficence (preventing or mitigating harm), personal dignity, and autonomy, the appreciation of which paves a way for fidelity and trust within the researcher-participant relationships (Kapp 2006).

In general, for each project that anticipates the participation of people and/or collection of human biological samples, the local Ethical Committee approval is a strictly obligatory condition. The task for the Ethical Committee is to examine whether any research project meets the following requirements: evaluation of possible physical and psychological risks for recruited subjects; description of the importance of new knowledge that is expected to be achieved from the studies; provision of means to guarantee the equitable selection of subjects; obtaining informed consent based on individual's awareness about the purposes of the research; correspondence of the project to its expected duration; acceptable nature of any interventions/experiments; and recognition of the right of volunteers to refuse consent or to withdraw consent at any time without being subject to any form of discrimination, in particular regarding the right to medical care (Council of Europe 2005; Matthews et al. 2005; Kapp 2006; Ezzat et al. 2010). The aim of the present review is to update current knowledge in ethical aspects of research on older people, by focusing on a few selected and interrelated topics, such as recruitment of participants, obtaining informed consent, and biobanking of DNA, cell and tissue samples. Given the promising potential of the use of human stem cells (hSC) in the research (Blair McCormick and Huso 2010; Doerflinger 2010; Goldstein 2010; Dresser 2010), the ethical aspects of application of hSC technologies in research and cure of diseases including the age-related maladies are discussed as well (Table 1). On the whole, this review
Table 1 Main issues for ethical evaluation in aging research

1. Recruitment of older participants

Establishment of inclusion and exclusion criteria

Assessment of benefit:burden ratio

Consideration of sex and gender differences

2. Obtaining informed consent from older participants

Assessment of capacity to provide informed consent in older participants

Description of proposed study, experimental nature and procedure

Assessment of potential risks and benefits to older participants

Protection of privacy

3. Biobanking of DNA/tissue/cell samples

Elaboration of security measures for the protection of biosamples

Identification of biosamples

Consideration of future use of the cells and tissues donated by the participants

4. Stem cell research and application

Identification of benefits and limitations on the use of hSCs in research and therapy of age-related diseases and frailty

represents a part of deliverables of the ongoing EC 7th Framework programme project MYOAGE "Understanding and combating human age-related muscle weakness" started in 2009.

\section{Recruitment of older people}

Although the population of older people is growing in developed countries, the older adults are still underrepresented in health-related research due to health problems, social and cultural barriers, and impaired capacity to provide informed consent (Mody et al. (2008). Accordingly, strategies to overcome these obstacles through creating a basis for respectful consideration and accommodation of the interests of participants, their families, investigators, caregivers, funding agencies, institutions, providers, and communities have been outlined (Mody et al. 2008). The first dimension of strategies comprises identification of the general goals such as obtaining of representative samples, promotion of participation, consideration of feasibility, and retention of participants. The second dimension of strategies is directed to the specific phases of research, such as study design, pilot studies 
and study implementation. To facilitate work in these stages, the formation of advisory board, consisting of representatives of all interested parties, is recommended. The advisory board can provide valuable and expert information about sources of potential participants, helps to anticipate the needs and concerns of community, communicates with the research and funding institutions, and promotes awareness of community members about ongoing research (Mody et al. 2008).

For successful recruitment and retention of older people, it is important to assess and maximize the benefit:burden ratio (Mody et al. 2008; Marshall 2006) (Table 1). The benefits to participants may comprise "compressed morbidity" and/or "decelerated aging" through provision of appropriate diagnostic tests, helpful treatments, services, and social instructions, in association to a positive effect of recognition of one's contribution (Fries 2000). Burdens include risks (e.g., potential health complications, discomfort due to tests and loss of privacy) and costs (e.g., the financial and time costs for participants and travel requirements). For example, anti-aging hormone replacement therapy may promote cancer, which should be considered as a considerable risk. Both the benefits and risks must be made clear for participants, usually by listing them in informed consent forms. To determine the appropriate benefit:burden ratio, the pilot tests of recruitment must be performed through primary interviewing the potential participants about the perceived benefits and burdens. Also, feedback from advisory boards can be useful for that purpose. One of the simple and effective ways to reduce burden is to minimize the proportion of invasive tests or procedures in the assessment protocols. To increase the participation, home assessment of participants can be foreseen, which, by reducing the burden for participants, can also increase the benefit:burden ratio.

Any research project designed to understand and combat age-related biological changes and diseases should adequately monitor the sex and gender differences that strongly influence the biological variability and presentation of symptoms and diseases. In their application in human studies the terms sex and gender should be clearly defined in the research project description. As stated by Wizemann and Pardue (2001) and referred to by Holdcroft (2007), sex is defined as "the classification of living things, generally as male or female according to their reproductive organs and functions assigned by chromosomal complement". Gender is defined as “a person's self-representation as male or female, or how that person is responded to by social institutions on the basis of the individual presentation. Gender is rooted in biology and shaped by environment and space". Because gender is considered to be a human trait (Wizemann and Pardue 2001), this term should be assigned to studies concerning human subjects. Gender has been identified as an important determinant of health which interacts with many factors, including biological material and cultural resources (Lawrence and Rieder 2007). Understanding the relationship between gender and health requires analysis of the unequal distribution of power and economic resources between men and women. Thus, it is important for any study on ageassociated pathologies to obtain "personal" data on education, job and entity of social network, as indices of social impact of man or woman. The recent review illustrates this approach by outlining the gender dependent differences of mentally ill subjects, taking into account many social-cultural aspects in correlation with treatment needs and responses (Judd et al. 2009).

Moreover, marked differences exist in patterns of health that affect men and women. Some habits or conditions are more prevalent in one sex than the other, representing either distinct risks or requiring different interventions for men and women. These differences may stem from specific biological characteristics of women and men (i.e., reproductive, genetic, hormonal and metabolic features, all associated to the sex), distinct habits in the daily life of men and women (i.e., smoking, drinking or consuming a less healthy food, all associated to the gender) and social network variations, all these factors interacting in complex ways. It has been suggested that the earlier research bias included mainly men without considering possible differences between the sexes. Currently, most of the studies consider participation of women and men, in order to improve the sensitivity to sex and gender factors (Moerman et al. 2007). However, this requirement can not be absolute. In some geographical area, for example, male centenarians could be rare in comparison with female ones, which renders assessment of both genders impossible (Franceschi et al. 2000).

It has been shown that the female muscle shows higher expression levels of transcript species related 
to cytoskeleton/contractile apparatus, mitochondrial processes and protein, lipid and amino acid metabolisms than does the male muscle (Yoshioka et al. 2007). In addition, the male and female subjects differ in the extent of age-related loss of muscle strength and mass in vastus lateralis muscle (Fulle et al. 2005). It is therefore strongly recommended that studies aimed at revealing the mechanisms of sarcopenia in older persons should equally address the male and female subgroups.

\section{Ensuring meaningful consent by older participants}

Freely given informed consent represents a cornerstone of ethical framework of any project with involvement of human participants. The purpose of informed consent is to promote autonomy (self-determination), protect a research subject from undesired treatment or interference, and provide her/him certain beneficence and help in making medical care decisions to maximally correlate with her/his personal values and needs (Ivashkov and Van Norman 2009; Moye and Marson 2007). A detailed analysis of the literature on informed consent has revealed that the capability of older subjects to understand the information provided by researchers may be compromised due to high prevalence of impaired cognition, hearing, speech, and vision. Therefore, effective strategies of improving understanding of information by older subjects should be applied when preparing the materials, forms, policies, and procedures for obtaining informed consent (Sugarman et al. 1998). The appropriate and meaningful valid consent should contain the following two main elements: (i) sufficient and understandable information provided to participant prior to consent and (ii) capability to give a free consent.

\section{Sufficient and understandable information}

From the information given to subject she/he should understand the overall research plan and main aims of research. To reach this, the main goals of the study should be shortly and clearly defined by the researchers. The persons concerned should understand the nature and duration of the procedures related to investigations. They should also understand the possible risks and benefits and be aware of their legal rights and means of confidentiality of personal data. While preparing the information for informed consent, it is worthwhile to consider that the participating subjects and the researches (e.g., medical doctors) may have somewhat different views on the content of information received/provided. The study performed by Newton-Howes et al. (1998) has revealed that the patients wish to be informed about the following aspects of the study: the major risks, outcome (quality and quantity of life), and consequences of not undergoing the testing procedures. The researches rather emphasize the general nature of the study and consequences of the testing procedures. Obviously, the interests of research subjects and researches should be balanced in the content of information given to the subjects that facilitates receiving of their consent.

There is an ethical question of raising hopes and expectations that the informed consent should deal with. This issue could be reasonably approached if in the phase of planning and progress of the study the researchers try to monitor all elements/stages of the research in terms as to what extent and how it improves our understanding in mechanisms of aging and associated impairment of health (i.e., how much this projects is "on the elderly") and leads to means applicable to combat age-related degeneration (e.g., muscle frailty) and increase the health span (i.e., how much this project serves "for the elderly") (Matthews et al. 2005). In other words, the hypotheses and research protocols should be evaluated in terms of their relevance to two main paradigms: (i) are they addressed to reduce morbidity caused by chronic illnesses underlying aging process and/or (ii) are they addressed to decelerate age-related disorders, e.g., through targeting the fundamental processes of gene regulation, signalling and metabolism altered by age? To answer these questions, the potential effects of interventions such as exercise, altered nutrition, hormonal replacement, and pharmacological treatment have to be estimated. Also, the social impact of the project has to be evaluated. It is useful to keep in mind that from the perspective of older person the strength and outcome of the project are related to its power to substantiate and elaborate the practical measures for improving her/his health. Only after evaluation of all these aspects the decisions can be made about the benefits that the project truly affords for given individual. The research subjects must be 
informed about whether and how they benefit directly or indirectly from the research (Matthews et al. 2005). The direct benefits may comprise diagnostic tests, helpful treatments, services, social instructions, recognition of subjects' contribution and advices for improving her/his quality of life. The indirect benefits can be described by explaining how she/he can help others by donating biosamples or participating in the functional studies. In any case, the expected benefits declared to participants must be realistic, i.e., be connected to the context of real human biology. It is not ethical to use rhetoric, such as promises of antiageing treatment (Turner, 2004). A short and userfriendly overview of the project, which covers its main scientific, ethical and social aspects and lists the expected benefits, is recommended to be presented in the information sheets.

When the research subject is asked for permission to take a tissue specimen, the type, amount, and the way of taking of the specimen should also be clearly described in informed consent. If the tissue is used for genetic study (e.g., DNA analysis), this aspect should be made clear for the subject, and she/he should be permitted to refuse donation of tissue for genetic analysis. A general and important requirement for study design is that it is not ethical (i) to collect biological data without having the corresponding phenotypic data from the same subject, and (ii) to collect more personal and biological data than could be processed in the following stage of analysis. Therefore, any research project needs to be continuously monitored and validated in quantitative terms, in order to avoid unnecessary accumulation of biomaterials (blood, muscle) and personal data.

\section{Capability to give a free consent}

Understanding the aims and content of research and her/ his freedom is largely based on decision-making capacity of the research subject. Attention to this parameter is increasing due to dramatic rise in the prevalence of cognitive deficiency and medical comorbidities among the older individuals. The capacity to consent to medical treatment and research is generally defined as "the ability to understand significant benefits, risks, and alternatives to proposed health care and to make and communicate a health care decision" (National Conference of Commissioners on Uniform State Laws, 1993, cited by Moye and Marson 2007).
From the perspective of researcher the term "capacity" refers to dichotomous (yes or no) judgement as to whether a subject can perform a specific task (e.g., driving) or make a specific decision (e.g., consenting to health care or research) (Moye and Marson 2007).

It has been suggested that the sensitivity of capacity assessment can be enhanced through shifting from determination of diagnosis of underlying incapacity toward recording the alterations in the specific domains of functional abilities (Moye and Marson 2007; Karlawish 2008). This novel model presumes four core abilities for being tested: (i) expressing of choice-the ability to convey (state) a decision regarding to treatment choice; (ii) understandingthe ability to comprehend the meaning of information, such as details of research protocol, diagnostic and treatment-related information including the risks and benefits; (iii) appreciation-the ability to recognize how given information applies to person, in relation to diagnosis, treatment and consequences to her/his situation; (iv) reasoning - the ability to rationally evaluate and compare treatment alternatives, to compare options and deduce the consequences of choices in a logically consistent manner.

A widely accepted approach to measuring the decision-making ability is to ask an individual a series of questions that assess alleged ability, followed by scoring the answers based on relevant criteria. Testing of these abilities in different sets of older populations has revealed that $44-69 \%$ of older adults hospitalized or living in nursing homes exhibit impaired capacity to consent to medical treatment. The consent capacity is reduced among individuals with dementia compared with healthy control individuals. In general, comprehension is negatively related to age and depression scores, but positively related to other indices such as IQ, reading comprehension, social support level, mental status, and community-dwelling ability (Krynski et al. 1994). It is now known that as the prevalence of cognitive impairment increases with age, the ability to make decisions progressively fails. However, particular abilities may become compromised at different stages of development of cognitive impairment. For example, among persons with very mild- to moderate-stage Alzheimer's disease, the abilities to choose and reason are relatively well preserved, but understanding and appreciation of information are markedly limited (Karlawish 2008). Distinctive progress has 
been made in revealing the clinical phenotypes of cognitively impaired persons who nevertheless have retained their capacity to consent. These persons belong to a subset of patients who have preserved awareness of their diagnosis, symptoms and prognosis and can be regarded as acceptable for recruitment in aging research. In general, correct assessment of cognitive function appears to be an important instrument in predicting the survival of older individuals (Duff et al. 2009). This is substantiated by several experimental findings inferring that impaired cognition is indicative of brain illness, reduction of general adaptive capacity, and impaired cellular immunity (Duff et al. 2009).

A practical assumption is that even though the older subjects present memory trouble, they are still able to give the valid consent. Accordingly, the informed consent model should recognize that memory troubles are not criteria for excluding the subjects from the research. At the same time, care must be taken that the information given matches to the reading ability and comprehension of the subjects studied. This requirement assumes a prior assessment of vision, hearing, and mental status of the participants.

Amongst older people, three levels of capacity to consent can be distinguished: (i) understanding and consent is clear, (ii) it is not possible to judge whether a person has understood, and (iii) understanding should be aided by family members or carers (substituted judgement, proxy consent, surrogate decision making) (Matthews et al. 2005). Substituted judgement is invoked in cases when seriously ill research subject (patient) lacks decision making capacity and has not provided advanced directive before her/his illness. The concept of substituted judgement is based on "asking what the patient would have wanted if he or she could tell us" (Torke et al. 2008). Both the family members and medical doctors (researches) as surrogates are involved in getting answer to this question and, finally, making a decision. The basic requirement in this process is that the decision should maximally support the patient's autonomy and her/his rights (i.e., receive treatment) even though she/he has lost the decision making capacity. Substituted judgement has been proven to be helpful in shifting focus from the desires of family members to those of the patients, thus easing the burden of responsibility on family members while making life and death decision for their loved ones.
Nevertheless, the concept of substituted judgement has met serious criticism on the following basis: (i) individual's preferences can change over time; (ii) the decisions made by patient and her/his family members or doctors do not concord entirely; (iii) many of the patients would like to rely on the preferences of their family members for decisions; and (iv) the concise legal basis for substituted judgement is still undeveloped (Kim et al. 2004). Therefore, the alternative models of decision-making have been proposed. One of these models is termed as the "best-interest standards" based on community norms. It sets the limits on types of choices that surrogates can make and leads to development of standards for the end-of-life care. However, this approach is limited because establishment of standards requires a too long period of discussing for reaching consensus within the community and appears not to consider correctly the values and interests of an individual. Another model, "the patient's life story-respect for persons" represents a narrative approach and rests on decisions made by family members through consideration the patient's own life choices. In this case the personal interests, although reflected by the family members, can be appreciated and the consensus about the optimal treatment of patient achieved (Torke et al. 2008).

\section{Collection of human biosamples and setting up biobanks}

Biobanks are collections of human biological tissue specimens-organs, tissue, blood, cells and other body fluids-together with related information on subject's phenotypes and health status (Elger and Caplan 2006; Hawkins 2010; The International Stem Cell Banking Initiative 2009). Based on advances in molecular genetics and stem cell research, the biobanks are considered as an important resource for research aimed at understanding the mechanisms underlying human diseases (Auray-Blais and Patenaude 2006; Hawkin's 2010; Nyika 2009). Human material and data, if related to donor age and assessed by molecular and genetic research may strongly promote understanding, combating and preventing the age-associated changes in human body as well.

As reviewed by Hawkins (2010) and Blair McCormick and Huso (2010), increasing development and use 
of biobanks has triggered a hot debate on ethical issues related to obtaining informed consent, privacy, protection, and data sharing. One of the most controversial and yet unsolved issues is the principle of consent applicable to biobanks. The obtaining of informed consent is complicated due to several reasons. First, the specimens may have been collected prior to their use in research. Second, the range and scope of originally proposed research based on the given specimens may change depending on the progress in development of new techniques (e.g., high-throughput sequencing). These circumstances lead to question about how could an informed consent be obtained for unknown future research uses (Kapp 2006; Hawkins 2010; Blair McCormick and Huso 2010).

The necessity to maintain privacy and confidentiality by biobanks adds another dimension to the problem. The American Society of Human Genetics has distinguished four types of identification of samples for research purposes: (i) anonymous: biological materials that were originally collected without identifiers and can not be linked to their sources (donors); (ii) anonymized: biological materials that were originally identified, but have been irreversibly stripped of all identifiers and therefore can not be linked to their sources; (iii) identifiable or coded or traceable: biological materials that are unidentified for research purposes, but can be linked to their sources through the use of a code; (iv) identified: biological materials to which identifiers, such as name, donor number, clear pedigree location, are attached and made available to the researchers (Godard et al. 2003; Auray-Blais and Patenaude 2006). Obviously, that large variety in sample identification procedures can bring about some ambiguities and ethical concerns. For example, anonymizing of the biospecimens helps to protect donors against accidental data release or discrimination, but eliminates her/his possibility to withdraw consent for the continued use of her/his sample (Hawkins 2010). Another concern is related to sharing of samples between the biobanks and research institutions (Hawkins 2010; Watson et al. 2010). On the one hand, collaboration of researchers through using the same biosamples may significantly increase the potential of research. On the other hand, the donors may lose control over their donated specimens and data and/or may become unable to withdraw their specimen or data from research (Hawkins 2010). As a solution to these problems, it has been suggested that studies aimed to be completed in the future do not require an additional informed consent if (i) the leftover specimens are being used, (ii) the specimens are accompanied by only minimal clinical information (age, sex and laboratory results), and (iii) the specimens are not individually identifiable (Kapp 2006). However, these arguments are confronted with assumption that "research on stored biological samples is still research" and that the subject's fundamental right to decide whether to give or not the tissue specimen should always be ensured (Sade 2002). As another solution, a concept of "broad" consent is proposed. This type of consent requires only general information about the research planned and permits researchers to carry out research, even if the research project is in its initial state of definition (Hawkins 2010). Accordingly, the informed consent used by researchers in some genetic or genomic studies includes a statement to the effect that samples will be stored for future genetic or genomic studies (Nyika 2009). The third option is proposed by the Nuffield Council on Bioethics Report "Human tissue: ethical and legal issues" (1995) which recommends that "human biological material obtained for use in research should be treated as gifts" (Medical Research Council 2001). Which of the concepts will prevail should be cleared out in future discussions.

\section{Stem cell research and its implications for solving the age-related problems}

Human stem cell (hSC) research is increasingly gaining attention among scientific and medical communities. Based on significant advances in this research, a new field-regenerative medicine has emerged, with holding promises of opening novel possibilities in the repairing or replacing tissue or organ function lost due to aging, chronic diseases and congenital defects. At the same time, hSC research has raised novel and serious ethical concerns with respect to the source, standardization, banking and distribution of hSCs, obtaining of informed consent, and expectations for clinical treatment (Hovatta et al. 2010; Lo et al. 2010; Luna and Salles 2010; Ilkilic and Ertin 2010; Árnason 2010; Kawakami et al. 2010).

The hSCs include several subclasses of the cells. One of them is termed as the human embryonic stem cells (hESCs), for which there are three sources available: (i) already existing embryonic stem cell 
lines; (ii) embryos left unused after in vitro fertilization procedures ("spare" embryos); and (iii) embryos created by means of somatic cell nuclear transfer technique. Notably, the hESCs based research has brought forward striking ethical controversies (Lo and Parham 2009) hotly debated within religious, historical, cultural, and medical sectors of the public. According to one of the dominant views, research with hESCs is inherently immoral because it requires destruction of an embryo which has the potential to develop into a viable human being and, as being actually a living members of the human species, has interests and basic right not to be killed, even not for human betterment (Bringnier and Gewirtz 2010; Doerflinger 2010). Using stem cells created by means of nuclear transfer has deserved especially strong criticism, as by virtue of their potential to generate a complete embryo these cells can be used for cloning of human beings (Bringnier and Gewirtz 2010). The entirely opposing view is that the embryo or blastocyst is nothing more than a clump of cells that can be used for research without restriction (Lo and Parham 2009). To date, there exists no acceptable and single solution to the problem. Instead, as Doerflinger (2010) has pointed out, one can notice increasing divide between an old ethics, based on traditions on inherent human rights, and a new utilitarian type of ethics, which, being more suited to technological progress, cost/benefit assessment and social planning, tends to relativize the value of individual in attempt to serve the greater good for a greater number of individuals, but potentially at the expense of weaker or unproductive ones. This approach, closely related to the concepts of "situation ethics" ("goal-oriented thinking", "end justifies the means") argues that the moral character of our actions depends on its consequence in a given situation. The weakness of "situation ethics" lies in the lack of standards "for judging whether a given action produces a surplus of good over bad consequences and so is justified" (Doerflinger 2010).

Ethical concerns related to research on hESCs have prompted investigators to seek for other sources of stem cells. In this regard, adult stem cells appear to offer an acceptable alternative to embryo research (Lo and Parham 2009). Adult stem cells have been identified in different tissues including skin, muscle, intestine, liver, brain and bone marrow, and they can differentiate into specialized cells. It is expected that exploring the stem cells enhances the chances for revealing the mechanisms of cell differentiation and tissue regeneration. For example, adult skeletal muscle contains an abundant and highly accessible population of muscle stem and progenitor cellssatellite cells. In adult muscle, the satellite cells are quiescent under normal physiological conditions. However, in response to signals resulting from exercise or injuries, satellite cells become activated, followed by proliferation, self-renewal and differentiation into mature muscle cells. Muscle satellite cells represent an excellent model system to explore adult stem cell biology and are also potentially ideal candidates for cell therapies in muscle diseases (Kuang and Rudnicki 2007). Satellite cells, in fact, are the most abundant and most accessible stem cells in our body, and they can be well studied considering the availability of well established in vivo muscle injury models and in vitro culture techniques (Negroni et al. 2009). However, despite the promising characteristics of adult stem cells, for several reasons these cells appear less attractive than embryonic stem cells as sources for research and therapeutic application. Firstly, adult stem cells are few in number and it is difficult to isolate them from tissues. Secondly, as they cannot be pluripotent like embryonic stem cells, they give rise to only a limited number of cell types. Thirdly, because these cells are adult they have accumulated a lifetime genetic mutations (Hug 2005). For all the abovementioned reasons it would not be possible to use adult stem cells as effectively as embryonic ones. Weighing the advantages and disadvantages of adult and embryonic stem cells has resulted in consensus among the scientists in that both stem cell types may be required depending on the aims of research (Hug 2005). At the same time, several other methods of deriving stem cells have been developed that raise fewer ethical concerns. For example, human umbilical cord has been found to be novel and promising alternative source of stem cells. More interestingly, the discovery of possibilities to induce human pluripotent stem cells (reprogrammed somatic cells) has provided the researches with principally novel type of stem cells application which likely resolves the ethical problems related to the use of hESCs and avoids the complications arising from the use of adult stem cells (Moore et al. 2006).

After having discussed the general ethical issues involved in hSC research, it would be interesting to 
consider the problems related to application of advances in this field in solving the age-related problems. In fact, there exists an evidence that the hSCs represent appropriate objects for studying the mechanisms of age related changes in fundamental processes of cell proliferation and differentiation, e.g., in cultures of human myoblasts derived from satellite cells (Bigot et al. 2008; Beccafico et al. 2007). Nevertheless, like any investigation based on hSCs (Lo and Parham 2009), the aging studies may also be hindered due to difficulties in obtaining of appropriate consent from a subject/patient. One of the major problems here is that despite exaggerated expectations and substantial funding, the therapeutic benefits of hSC research and application of these cells to cure ageing-related conditions are still unpredictable. In addition, the scientists are currently unable to avoid potential risks, e.g., development of teratomas and immunological reactions after transplantation of hSCs to the recipient (Goldstein 2010; Dresser 2010; Hyun 2010a). The experience from attempts to understand and cure Alzheimer's disease serves as good illustration of these complex problems. Although the stem cells technologies have been considered as most potential means to treat this disease, the application of hSCs for this purpose has turned out to be unsuccessful. Inaccurate characterization and standardization of cell types, inappropriate methods for purification of stem cells, inadequate technologies of programming of somatic cells, and insufficient clinical trials-each of these shortcomings or all together may cause potential failure in clinical application of stem cell technology (Goldstein 2010). Despite of these limitations, there is an explicit pressure for translation of knowledge obtained in hSC research to clinical practice. The application of hSCs for treatment may become necessary for patients having serious or immediately life-threatening disease which can not be cured by traditional drug therapy. For those, participation in $\mathrm{hSC}$ research or use of hSCs for treatment may be the only option. These patients desperately seek for therapy in so called "stem cell clinics" all over the world, among which many may lack the relevant competence. As a result, the risks to patients of inadequate or even harmful treatment stand high (Hyun 2010a, b). To protect these patients from unwanted consequences of treatment and to develop innovative therapies grounded by science-based approaches, the legal and ethical conditions have been issued by US Food and Drug Administration and International Society for Stem Cell Research (ISSCR) for provision of stem cell-based therapy for individual patients and enabling them to participate in clinical trials (Hyun 2010a, b). From the ethical point of view it is required that before recruitment of individuals to hSC research or clinical trials, the researchers/physicians should honestly inform them about the aims and risks of the studies planned, with special emphasis on explaining that application of stem cells for cure of their diseases may not result in clinical benefits, in order to avoid unrealistic hopes (Dresser 2010, Hyun 2010a, b). The ISSCR guidelines stress the necessity of supplementation of human research review committees with members having expertise in the field of stem cell research. This approach can improve the assessment of the scientific rationale for hSC-based interventions (Hyun 2010a). It is obligatory for donors and patients to give well-informed written consent which demonstrates their understanding of the involved risks and admittance of the lack of proof of clinical benefits. For very ill patients it is especially important to carefully and responsibly consider whether and to what extent the patient is able to make informed decision for participating in the study (Blair McCormick and Huso 2010).

\section{Conclusions}

Aging of European population associated with increased illness and frailty among older people has stimulated intensive research aimed at counteracting senescence and postponing the onset of age-related diseases. Success in this field strongly relies upon the efficient engagement of older subjects in the study projects. Application of ethical standards which adequately consider the vulnerability of older people due to compromised health, reduced mobility and limited capability to give informed consent for participation, serves as an important tool to achieve this goal. This paper reviews the main ethical principles applicable to aging research, with emphasis to address novel trends in the field. It is concluded that a good ethical platform is the one which precisely defines the main goals and strategies not only for respectful protection of the subject's 
interests, but also for ensuring high quality of research. A first set of strategies, based on evaluation of (i) inclusion and exclusion criteria, (ii) gender differences, and (iii) benefits and risks to participants, is meant to guarantee recruitment and formation of study group, which correctly represents the aged population and involves subjects who are highly motivated to participate in the research project. The second group of strategies is related to obtaining relevant written informed consent. This document should precisely describe (i) the study goals, (ii) experimental or clinical interventions, (iii) direct and indirect benefits and potential risks for participants, (iv) the type and amount of biosamples taken, and (v) means for protection of privacy and rights of the participant. It is required that the information given matches to the reading, cognitive, comprehension, and decision-making abilities of the subjects studied, which can be monitored by adequate tests. In cases that these abilities are either limited or lacking, a substituted judgement by family members and physicians/researchers can be applied, with an obligatory condition that the decisions made serve the individual's best interests.

The issues related to collection and use of human biological samples (DNA, tissues, cells) represent a complicated field of ethical concerns. The concepts that it is not ethical to collect biosamples without association of phenotypic data, or to accumulate them in amounts beyond capacities for their processing, are generally accepted. At the same time, the principles of giving the informed consent for storing the samples are still not clear and therefore under ongoing discussion. Here the most difficult and unanswered question is about how can donors agree with the future use of biosamples that they already have donated.

The advent of hSC research has sparked hot debates on ethical grounds. Undoubtedly, progress in this field has opened principally new opportunities for understanding the fundamental issues of development and differentiation, including aging related changes in these processes. Perhaps, the hopes that hSC technology offers novel therapeutic modalities through repair or replacement of worn-out tissues in aged organism are most intriguing. This perspective has serious ethical caveats, however. For example, regarding the ageing related neurodegenerative and cardiovascular diseases the therapeutic benefits of application of hSC technology are unpredictable and the potential risks are largely unavoidable. These circumstances clearly argue against ethical acceptance of hSC-based therapy. However, for many patients with serious disease, the application of hSCs may be the only option to cure their disease, and they have rights for seeking that possibility. This means that it is time to elaborate and utilize the ethical platforms which are grounded by best scientific knowledge available, and focus on good patient care (not for research) and permit to conduct innovative hSC-based therapies, even outside the clinical trial context. This is a new value-based paradigm committed to motivate medical innovation in association with protection of the patient's right for being cared.

Acknowledgment This review was supported by EUMYOAGE project, FP7 223576, and by the grants of Estonian Science Foundation No 7823 and 8736.

\section{References}

Árnason V (2010) Bioethics in Iseland. Camb Q Healtc Ethics 19:299-309

Auray-Blais C, Patenaude J (2006) A biobank management model applicable to biomedical research. BMC Med Ethics 7:1-9

Beccafico S, Puglielli C, Pietrangelo T, Bellomo R, Fanò G, Fulle S (2007) Age-dependent effects on functional aspects in human satellite cells. Ann N Y Acad Sci 1100:345-352

Bigot A, Jacquemin V, Debacq-Chainiaux F, Buttler-Browne G, Toussaint O, Furling D, Mouly V (2008) Replicative aging down-regulates the myogenic regulatory factors in human myoblasts. Biol Cell 100:189-199

Blair McCormick J, Huso HA (2010) Stem cells and ethics: current issues. J Cardiovasc Trans Res 3:122-127

Bringnier AC, Gewirtz AM (2010) Embryonic and adult stem cell therapy. J Allergy Clin Immunol 125:S336-S344

Council of Europe (2005) Additional protocol to the convention on human rights and biomedicine concerning biomedical research, Strasbourg, 2005. European treaty series no. 195

Doerflinger RM (2010) Old and new ethics in the stem cell debate. J Law Med Ethics 38(2):212-319

Dresser R (2010) Stem cell research as innovation: expanding the ethical ad policy conversation. J Law Med Ethics 38(2):332-341

Duff K, Mold JW, Gidron Y (2009) Cognitive functioning predicts survival in the elderly. J Clin Exp Neuropsychol 31:90-95

Elger BS, Caplan AL (2006) Consent and anonymization in research involving biobanks. EMBO Reports 7:661-666

Ezzat H, Ross S, von Dadelzen P, Morris T, Liston R, Magee LA (2010) Ethics review as a component of institutional 
approval for a multicentre continuous quality improvement project: the investigator's perspective. Health Service Res 10:223 http://www.biomedcentral.com/1472$6963 / 10 / 223$

Franceschi C, Motta L, Valensin S, Rapisarda R, Franzone A, Berardelli M, Motta M, Monti D, Bonafè M, Ferrucci L, Deiana L, Pes GM, Carru C, Desole MS, Barbi C, Sartoni G, Gemelli C, Lescai F, Olivieri F, Marchegiani F, Cardelli M, Cavallone L, Gueresi P, Cossarizza A, Troiano L, Pini G, Sansoni P, Passeri G, Lisa R, Spazzafumo L, Amadio L, Giunta S, Stecconi R, Morresi R, Viticchi C, Mattace R, De Benedictis G, Baggio G (2000) Do men and women follow different trajectories to reach extreme longevity? Italian Multicenter Study on Centenarians (IMUSCE). Aging (Milano) 12:77-84

Fries JF (2000) Compression of morbidity in the elderly. Vaccine 18:1584-1589

Fulle S, Belia S, Di Tano G (2005) Sarcopenia is more than a muscular deficit. Arch Ital Biol 143:229-234

Godard B, Schmidtke J, Cassiman J, Ayme S (2003) Data storage and DNA banking for biomedical research: informed consent, confidentiality, quality issues, ownership, return of benefits. A professional perspective. Eur J Hum Gen 11:S88-S122

Goldstein L (2010) Why scientific details are important when novel technologies encounter law, politics, and ethics. J Law Med Ethics 38(2):204-211

Hawkins AK (2010) Biobanks: importance, implications and opportunities for genetic counsellors. J Genet Counsel. doi:10.1007/s10897-010-9305-1

Holdcroft A (2007) Integrating the dimensions of sex and gender into basic life sciences research: methodological and ethical issues. Gender Med 4(Suppl B):S64-S74

Hovatta O, Stojkovic M, Nogueira M, Varela-Nieto I (2010) European scientific, ethical, and legal issues on human stem cell research and regenerative medicine. Stem Cells 28:1005-1007

Hug K (2005) Sources of human embryos for stem cell research: ethical problems and their possible solutions. Medicina (Kaunas) 41:1002-1010

Hyun I (2010a) The bioethics of stem cell research and therapy. J Clin Invest 120:71-75

Hyun I (2010b) Allowing innovative stem cell-based therapies outside of clinical trials: ethical and policy challenges. J Law Med Ethics 38(2):277-285

Ilkilic I, Ertin H (2010) Ethical aspects of human embryonic stem cell research in the Islamic world: positions and reflections. Stem Cell Rev Rep 6:151-161

Ivashkov Y, Van Norman GA (2009) Informed consent and the ethical management of older patient. Anesthesiol Clin 27:569-580

Judd F, Armstrong S, Kulkarni J (2009) Gender-sensitive mental health care. Australas Psychiatry 17:105-111

Kapp MB (2006) Ethical and legal issues in research involving human subjects: do you want a piece of me? J Clin Pathol 59:335-339

Karlawish J (2008) Measuring decision-making capacity in cognitively impaired individuals. Neurosignals 16:91-98

Kawakami M, Sipp D, Kato K (2010) Regulatory impacts on stem cell research in Japan. Cell Stem cell 6:415-418
Kim SYH, Appelbaum PS, Jeste DV, Olin JT (2004) Proxy and surrogate consent in geriatric neuropsychiatric research: update and recommendations. Am J Psychiatry 161:797-806

Krynski MD, Tymchuk AJ, Ouslander JG (1994) How informed can consent be? New light on comprehension among elderly people making decisions about enteral tube feeding. Gerontologist 34:36-43

Kuang S, Rudnicki MA (2007) The emerging biology of satellite cells and their therapeutic potential. Cell Press 14:81-91

Lawrence K, Rieder A (2007) Methodologic and ethical ramifications of sex and gender differences in public health research. Gender Med 4:S96-S105

Lo B, Parham L (2009) Ethical issues in stem cell research. Endocrine Rev 30:204-213

Lo B, Parham L, Cedras M, Fisher S, Gates E, Giudice L, Gould Halme D, Hershorn W, Kriegstein A, Rao R, Roberst C, Wagner R (2010) Research ethics: NIH guidelines for stem cell research and gamete donors. Science 372:962-963

Luna F, Salles A (2010) On moral incoherence and hidden battles: stem cell research in Argentina. Dev World Bioethics 10:120-128

Marshall J (2006) Life extension research: an analysis of contemporary biological theories and ethical issues. Med Health Care Philos 9:87-96

Matthews E, Haimes E, Duguet A-M, Clark BFC, Swine C, Touissant $\mathrm{O}$ (2005) Informed consent of very old patients and modern genomics. Biogerontology 6:81-84

Medical Research Council (2001) Human tissue and biological samples for use in research. Operational and ethical guidelines. MRC's website: www.mrc.ac.uk

Mody L, Miller DK, McGloin JM, Freeman M, Marcantonio ER, Maganizer J, Studensky S (2008) Recruitment and retention of older adults in aging research. J Am Geriatr Soc 56:2340-2348

Moerman CJ, Haafkens JA, Soderstrom M, Ràsky E, Maguire P, Maschewsky-Schneider U, Norstedt M, Hahn D, Reinerth H, McKevitt N (2007) Gender equality in the work of local research ethics committees in Europe: a study of practice in five countries. J Med Ethics 33:107-112

Moore KE, Mills JF, Thornton MM (2006) Alternative sources of adult stem cells: a possible solution to the embryonic stem cell debate. Gender Med 3:161-168

Moye J, Marson D (2007) Assessment of decision-making capacity in older adults: an emerging area of practice and research. J Gerontol 62B:P3-P11

Negroni E, Riederer I, Chaouch S, Belicchi M, Razini P, Di Santo J, Torrente Y, Butler-Browne GS, Mouly V (2009) In vivo myogenic potential of human $\mathrm{CD}_{133^{+}}$musclederived stem cells: a quantitative study. Mol Ther 17:1771-1778

Newton-Howes PA, Bedford ND, Dobbs BR, Frizelle FA (1998) Informed consent: what do patients want to know? N Z Med J 111:340-342

Nyika A (2009) Ethical and practical challenges surrounding genetic and genomic research in developing countries. Acta Trop 112S:S21-S31

Sade RM (2002) Research on stored biological samples is still research. Arch Int Med 162:1439-1440 
Sugarman J, McCrory DC, Hubal RC (1998) Getting meaningful informed consent from older adults: a structured literature review of empirical research. J Am Geriatr Soc 46:517-524

The International Stem Cell Banking Initiative (2009) Consensus guidance for banking and supply of human embryonic stem cell lines for research purposes. Stem Cell Rev Rep 5:301-314

Torke AM, Alexander GC, Lantos J (2008) Substituted judgement: the limitations of autonomy in surrogate decision making. J Gen Intern Med 23:1514-1517

Turner L (2004) Biotechnology, bioethics and anti-aging interventions. Trends Biotechnol 22:219-221
Watson RWG, Kay EW, Smith D (2010) Integrating biobanks: addressing the practical and ethical issues to deliver a valuable tool for cancer research. Nature Rev 10:646-651

Wizemann TM, Pardue ML (eds) (2001) For committee on understanding the biological contributions to human health: exploring the biological contributions to human health. Does sex matter? Institute of Medicine, National Academic Press, Washington DC, pp 17-19

Yoshioka M, Boivin A, Bolduc C, St-Amand J (2007) Gender difference of androgen actions on skeletal muscle transcriptome. J Mol Endocrinol 39:119-133 